\title{
Can the anxiety domain of EQ-5D and mental health items from SF-36 help predict outcomes after surgery for lumbar degenerative disorders?
}

\author{
Leah Y. Carreon, MD, MSc, ${ }^{1}$ Mladen Djurasovic, MD, ${ }^{1,2}$ John R. Dimar II, MD, ${ }^{1,2}$ \\ R. Kirk Owens II, MD, ${ }^{1}$ Charles H. Crawford III, MD, ${ }^{1,2}$ Rolando M. Puno, MD,,2 \\ Kelly R. Bratcher, RN, CCRP, ${ }^{1}$ Katlyn E. McGraw, BA, ${ }^{1}$ and Steven D. Glassman, MD ${ }^{1,2}$ \\ ${ }^{1}$ Norton Leatherman Spine Center, Louisville; and ${ }^{2 D e p a r t m e n t ~ o f ~ O r t h o p a e d i c ~ S u r g e r y, ~ U n i v e r s i t y ~ o f ~ L o u i s v i l l e ~ S c h o o l ~ o f ~}$
Medicine, Louisville, Kentucky
}

OBJECTIVE Studies have shown that anxious or depressed patients may have poorer outcomes after lumbar fusion. These conclusions were drawn from questionnaires specifically designed to measure anxiety and depression. The objective of this study is to determine if responses to the EQ-5D anxiety/depression domain or the items used to calculate the 36-Item Short-Form Health Survey (SF-36) Mental Component Summary (MCS) can predict outcomes after lumbar fusion surgery.

METHODS Patients enrolled in the National Neurosurgery Quality and Outcomes Database from a single center with 1-year follow-up were identified. The outcomes collected include the Oswestry Disability Index (ODI), EQ-5D, SF-36, and the back- and leg-pain numeric rating scales (range 0-10). Linear regression modeling was performed to predict the 1-year ODI scores using the EQ-5D anxiety/depression domain and the 14 items used to calculate SF-36 MCS.

RESULTS Complete data were available for 312 (88\%) of 353 eligible patients. The mean patient age was 58.5 years, $175(56 \%)$ patients were women, and 52 patients were smokers. After controlling for other factors, the item in the SF-36 that asks "Have you felt downhearted and depressed?" is the strongest predictor of the 1-year ODI score $\left(r^{2}=0.191 ; p=\right.$ $0.000)$ and 1-year EQ-5D score $\left(r^{2}=0.205 ; p=0.000\right)$. Neither the EQ-5D anxiety/depression domain nor the diagnoses of anxiety or depression were predictors of 1 -year outcomes.

CONCLUSIONS Patient responses to SF-36 item "Have you felt downhearted and depressed?" account for $20 \%$ of the variability of the 1-year ODI and EQ-5D scores and can be used by clinicians to screen for anxiety or depression in patients prior to lumbar fusion surgery. Clinicians may offer psychological support to these patients preoperatively in order to improve treatment outcomes.

http://thejns.org/doi/abs/10.3171/2016.2.SPINE151472

KEY WORDS outcomes; lumbar fusion; depression; anxiety; mental health

$\mathrm{S}$ EVERAL studies have shown that patients with anxiety or depression may have poorer outcomes after surgery for lumbar degenerative disorders. ${ }^{1,16,17,19,20,22}$ These conclusions were drawn from questionnaires specifically designed to measure anxiety and depression such as the Distress and Risk Assessment Method, ${ }^{12}$ Hospital Anxiety and Depression Scale, ${ }^{25}$ Minnesota Multiphasic Personality Inventory, ${ }^{6}$ and the Beck Depression Inventory. ${ }^{3}$ These questionnaires are not routinely administered in the spine surgery clinic.
Increasingly, patient-reported outcomes are routinely obtained in the clinic using the EQ-5D (http://archive. ahrq.gov/professionals/clinicians-providers/resources/ rice/EQ5Dscore.html) ${ }^{8}$ and SF-36 ${ }^{23}$ as generic health-related quality-of-life measures, as well as the Oswestry Disability Index (ODI) ${ }^{9,10}$ as a low-back disability measure. The EQ-5D ${ }^{8}$ has an anxiety/depression domain with 3 choices ("I am not anxious or depressed," "I am moderately anxious or depressed," and "I am extremely anxious or depressed"). The 36-Item Short-Form Health Survey (SF-

ABBREVIATIONS MCS = Mental Component Summary; $\mathrm{MH}=$ mental health; $\mathrm{N}^{2} Q O D=$ National Neurosurgery Quality and Outcomes Database; ODI = Oswestry Disability Index; SF-36 = 36-Item Short-Form Health Survey.

SUBMITTED December 14, 2015. ACCEPTED February 25, 2016.

INCLUDE WHEN CITING Published online May 6, 2016; DOI: 10.3171/2016.2.SPINE151472. 
$36)^{23}$ is composed of 36 items, and responses to 5 items are used to produce a mental health (MH) score. An additional 9 items that produce the vitality, social functioning, and role-emotional domains are used to produce the mental composite summary (MCS) score. The scoring algorithm used to produce the MH and MCS scores cannot be manually performed in the clinic. ${ }^{23}$ Thus, the use of the $\mathrm{MH}$ and MCS scores, as a tool to guide treatment for patients with lumbar degenerative disorders in the clinic, is limited.

The purpose of this study is to determine if patient responses to the EQ-5D anxiety/depression domain can be used as a tool to guide treatment. The other purpose of this study is to determine if a simpler method that uses the 14 items used to calculate the MH or MCS scores from SF-36 can be developed that in turn be used to guide treatment.

\section{Methods}

\section{Samples}

Patients from a single-center, multisurgeon, tertiary spine clinic who were registered in the National Neurosurgery Quality and Outcomes Database $\left(\mathrm{N}^{2} \mathrm{QOD}\right)^{2,14,15}$ and had undergone lumbar fusion with complete baseline and 12-month follow-up data by October 2014 were identified. As part of the $\mathrm{N}^{2} \mathrm{QOD}$ registry, the EQ-5D-3 level, ${ }^{8}$ ODI, ${ }^{9,10}$ back-pain scores (range $0-10$ ), and leg-pain scores (range $0-10)^{13}$ were determined prior to surgery and at 3 and 12 months after surgery. In addition, SF- $36^{23}$ was administered at the same time points.

\section{Statistical Analysis}

All statistical analyses were carried out using SPSS (version 21; IBM). Stepwise forward linear regression was conducted to predict the 1-year ODI scores using the EQ-5D anxiety/depression domain and the responses to the 14 questions that produce the MCS. The responses to the 14 items were unweighted and scored from 1 (best) to 5 (worst). To control for confounders, other known predictors such as indication for surgery, educational level, American Society of Anesthesiologists class, workers' compensation, insurance, and symptom duration were included in the model.

\section{Results}

\section{Descriptive Statistics}

Complete baseline and 12-month data were available for $312(88 \%)$ of 353 eligible patients. The mean age was $58.5 \pm 15.2$ years, $175(56 \%)$ patients were women, and 52 $(17 \%)$ patients were smokers. Based on the review of their medical records, 38 (12\%) patients had a medical history of anxiety (Table 1). The distribution of the responses to the EQ-5D anxiety/depression domain was statistically significantly different between the patients who had a medical history of anxiety and those who did not. In addition, patients who had a medical history of anxiety had a lower SF-36 score in both the MH domain and MCS score compared with those who did not have a medical history of anxiety.

Fifty-eight patients (18\%) had a history of depression (Table 2). The distribution of responses to the EQ-5D anx-
TABLE 1. Baseline EQ-5D anxiety/domain responses and SF-36 MH domain and MCS scores in patients with and without a diagnosis of anxiety*

\begin{tabular}{cccc}
\hline \multicolumn{1}{c}{ Variable } & No Anxiety & $\begin{array}{c}\text { Anxiety } \\
\text { Present }\end{array}$ & $\begin{array}{c}\mathrm{p} \\
\text { Value }\end{array}$ \\
\hline $\begin{array}{c}\text { No. of patients } \\
\begin{array}{c}\text { Response to anxiety/de- } \\
\text { pression domain }\end{array}\end{array}$ & 38 & \\
\hline $\begin{array}{c}\text { "I am not anxious or } \\
\text { depressed" }\end{array}$ & $106(34 \%)$ & $6(2 \%)$ & \\
\hline $\begin{array}{c}\text { "I am moderately anx- } \\
\text { ious or depressed" }\end{array}$ & $145(46 \%)$ & $22(7 \%)$ & \\
\hline $\begin{array}{c}\text { "I am extremely anx- } \\
\text { ious or depressed" }\end{array}$ & $23(10 \%)$ & $10(3 \%)$ & \\
\hline SF-36 domain score & & & \\
\hline Mean MH score (SD) & $40.70(12.47)$ & $34.09(14.04)$ & 0.004 \\
\hline Mean MCS (SD) & $38.73(13.27)$ & $32.11(12.96)$ & 0.008 \\
\hline
\end{tabular}

* Values are shown as the number of patients unless otherwise indicated.

iety/depression domain was statistically and significantly different between the patients who had a medical history of depression and those who did not. Patients who had a medical history of depression had lower SF-36 MH and SF-36 MCS scores compared with those who did not.

\section{Linear Regression Analysis}

After controlling for other factors, the item in the SF-36 that asks "Have you felt downhearted and depressed?" is the strongest predictor of the 1-year ODI score $\left(r^{2}=0.191\right.$; $\mathrm{p}=0.000)$ and 1-year EQ-5D $\left(\mathrm{r}^{2}=0.205 ; \mathrm{p}=0.000\right)$. Other significant predictors were smoking status and principal spine diagnosis. The use of a regression model other than linear regression did not improve the predictive value of the model. Neither the EQ-5D anxiety/depression domain nor medical histories of anxiety or depression were predictors of 1-year outcomes. The results of the multivariate regression analysis are presented in Table 3.

TABLE 2. Baseline EQ-5D anxiety/domain responses and SF-36 MH domain and MCS scores in patients with and without a diagnosis of depression*

\begin{tabular}{|c|c|c|c|}
\hline Variable & $\begin{array}{c}\text { No } \\
\text { Depression }\end{array}$ & $\begin{array}{l}\text { Depression } \\
\text { Present }\end{array}$ & $\begin{array}{c}p \\
\text { Value }\end{array}$ \\
\hline No. of patients & 254 & 58 & \\
\hline $\begin{array}{l}\text { Response to anxiety/depres- } \\
\text { sion domain }\end{array}$ & & & 0.000 \\
\hline $\begin{array}{l}\text { "I am not anxious or } \\
\text { depressed" }\end{array}$ & $104(33 \%)$ & $8(3 \%)$ & \\
\hline $\begin{array}{l}\text { "I am moderately anx- } \\
\text { ious or depressed" }\end{array}$ & $129(41 \%)$ & $38(12 \%)$ & \\
\hline $\begin{array}{l}\text { "I am extremely anxious } \\
\text { or depressed" }\end{array}$ & $21(7 \%)$ & $12(4 \%)$ & \\
\hline \multicolumn{4}{|l|}{ SF-36 domain score } \\
\hline Mean MH score (SD) & $41.27(12.42)$ & $34.03(12.98)$ & 0.000 \\
\hline Mean MCS score (SD) & $39.05(13.33)$ & $33.21(12.62)$ & 0.004 \\
\hline
\end{tabular}

* Values are shown as number of patients unless otherwise indicated. 
TABLE 3. Results of the stepwise logistic regression model

\begin{tabular}{|c|c|c|}
\hline Variable & $\begin{array}{l}\text { Standardized } \\
\beta \text { Coefficient }\end{array}$ & $\begin{array}{c}\mathrm{p} \\
\text { Value }\end{array}$ \\
\hline \multicolumn{3}{|l|}{ Independent variables included in model } \\
\hline $\begin{array}{l}\text { Baseline response to SF-36 Item "Have you } \\
\text { felt downhearted and depressed?" }\end{array}$ & -0.24 & 0.006 \\
\hline Smoking status & -0.24 & 0.000 \\
\hline Principal spine diagnosis & 0.16 & 0.003 \\
\hline \multicolumn{3}{|l|}{ Independent variables excluded from the model } \\
\hline Patient educational level & 0.17 & 0.944 \\
\hline American Society of Anesthesiologists grade & 0.44 & 0.963 \\
\hline Workers' compensation status & 0.23 & 0.997 \\
\hline Type of insurance & 0.46 & 0.952 \\
\hline Symptom duration & 0.83 & 0.990 \\
\hline Diagnosis of anxiety & 0.24 & 0.967 \\
\hline Diagnosis of depression & 0.44 & 0.944 \\
\hline $\begin{array}{l}\text { Baseline response to EQ-5D anxiety/de- } \\
\text { pression domain }\end{array}$ & 0.86 & 0.482 \\
\hline Baseline response to SF-36 items & 0.86 & 0.482 \\
\hline "Did you feel full of life?" & 0.88 & 0.645 \\
\hline "Have you been very nervous?" & 0.75 & 0.527 \\
\hline $\begin{array}{l}\text { "Have you felt so down in the dumps that } \\
\text { nothing could cheer you up?" }\end{array}$ & 0.50 & 0.376 \\
\hline "Have you felt calm and peaceful?" & 0.38 & 0.615 \\
\hline "Did you have a lot of energy?" & 0.50 & 0.752 \\
\hline "Did you feel worn out?" & 0.12 & 0.751 \\
\hline "Have you been happy?" & 0.32 & 0.522 \\
\hline "Did you feel tired?" & 0.30 & 0.745 \\
\hline $\begin{array}{l}\text { "During the past } 4 \text { weeks, how much of } \\
\text { the time has your physical health or } \\
\text { emotional problems interfered with } \\
\text { your social activities?" }\end{array}$ & 0.14 & 0.600 \\
\hline
\end{tabular}

\section{Analysis of Variance}

The 1-year ODI scores stratified by the responses to the baseline EQ-5D anxiety/depression domain are summarized in Table 4 and show that patients who chose the statement "I am not anxious or depressed" had better (i.e., lower) 1-year ODI scores compared with those who chose "I am moderately anxious or depressed," who in turn had better scores than those who chose "I am extremely anxious or depressed." Similarly, patients who at baseline responded with "All the time" to the SF-36 item "Have you felt downhearted and depressed?" had worse 1-year ODI scores compared with those who responded "Most of the time" and "Some of the time." The best 1-year ODI scores were seen in patients who responded "None of the time" or "A little of the time" (Table 5).

\section{Discussion}

Several studies have shown that patients with anxiety and/or depression may have poorer outcomes after lowback surgery compared with those who do not. 1,16,17,19,20,22 It would greatly benefit patients and physicians alike if a screening tool that can be easily administered and scored
TABLE 4. One-year mean postoperative ODI scores stratified by response to the EQ-5D anxiety/depression domain

\begin{tabular}{cccc}
\hline $\begin{array}{c}\text { Response to Anxiety/ } \\
\text { Depression Domain }\end{array}$ & $\begin{array}{c}\text { No. of } \\
\text { Patients }\end{array}$ & $\begin{array}{c}\text { Mean ODI } \\
\text { Score (SD) }\end{array}$ & $\begin{array}{c}p \\
\text { Value }\end{array}$ \\
\hline "I am not anxious or depressed" & 112 & $27.85(17.71)$ & $0.000^{*}$ \\
\hline $\begin{array}{l}\text { "I am moderately anxious or } \\
\text { depressed" }\end{array}$ & 167 & $39.80(21.35)$ & \\
\hline $\begin{array}{l}\text { "I am extremely anxious or } \\
\text { depressed" }\end{array}$ & 33 & $49.84(23.55)$ & \\
\hline * p value determined using 1-way ANOVA. & & & \\
\end{tabular}

was available to identify patients at risk for a poor outcome. Unfortunately, psychological tests are rarely administered to patients who present at a spine clinic. This may be due to several factors. Most spine specialists are not familiar with the administration and interpretation of these instruments; they may be wary of the patient's perception that they are being psychologically profiled. Also, the instruments cannot be readily scored without a complex algorithm. If a simple screening tool was available to screen patients for subclinical depression or anxiety, and if additional counseling or cognitive therapy can be provided prior to surgery, patient outcomes may be improved.

The current study shows that the patient's response to the SF-36 item "Have you felt downhearted and depressed?" is the strongest predictor of ODI scores at 1 year after surgery, accounting for $20 \%$ of its variability. The patient's responses to this one question can be easily interpreted by the clinician and help guide treatment decisions. Clinicians may offer psychological support preoperatively to patients who are at risk for poorer outcomes after lumbar spine surgery based on their responses to this question. This single question has also been found to be a strong, nonspecific predictor of affective or anxiety disorders and depression. ${ }^{4,24}$ It has also been found to be predictive of medical care usage ${ }^{18}$ and mortality in patients with endstage renal disease. ${ }^{21}$

Although one may expect that responses to the anxiety/ depression domain of the EQ-5D or a diagnosis of anxiety or depression to be stronger predictors of 1-year ODI scores, these factors were not strong predictors. This may be due to the number of responses available for each of these factors: 2 responses (yes or no) for the diagnosis of anxiety or depression, and 3 responses for the EQ-5D anxiety/depression domain. Larger sample sizes may be

TABLE 5. One-year mean postop ODI and EQ-5D scores stratified by responses to the SF-36 item "Have you felt downhearted and depressed?"

\begin{tabular}{lccc}
\hline \multicolumn{1}{c}{ Response } & $\begin{array}{c}\text { No. of } \\
\text { Patients }\end{array}$ & $\begin{array}{c}\text { Mean 1-Yr ODI } \\
(\text { SD })\end{array}$ & $\begin{array}{c}\text { Mean 1-Yr EQ-5D } \\
(\text { SD })\end{array}$ \\
\hline "All the time" & 27 & $52.43(21.28)$ & $0.44(0.23)$ \\
\hline "Most of the time" & 48 & $52.86(17.50)$ & $0.50(0.25)$ \\
\hline "Some of the time" & 66 & $38.11(19.61)$ & $0.63(0.22)$ \\
\hline "A little of the time" & 90 & $32.30(20.26)$ & $0.69(0.23)$ \\
\hline "None of the time" & 81 & $26.36(18.65)$ & $0.78(0.17)$ \\
\hline p value & & 0.000 & 0.000 \\
\hline
\end{tabular}


needed to detect strong correlations between the EQ-5D anxiety/depression domain and 1-year patient outcomes. Patient responses to these questions may have been collinear with their responses to the SF-36 item, such that these factors were dropped from the final stepwise regression analysis. In addition, the responses to the SF-36 item may identify subclinical anxiety or depression that can affect 1-year clinical outcomes after lumbar fusion surgery or it may be measuring a different latent variable.

The second strongest independent predictor of 1-year ODI scores is the patient's smoking status. This is not a new finding and has been established to be predictive of poor outcomes after lumbar fusion surgery. Although poorer outcomes in smokers are associated with the high risk of nonunion, ${ }^{5,7}$ poorer outcomes persist even with improved fusion rates. ${ }^{11}$ Similar to subclinical anxiety or depression, smoking status also has the potential to be modified with behavioral and cognitive therapy. In the current study, the only other statistically significant independent predictor of the 1-year ODI scores is the principal diagnosis, a factor that cannot be modified prior to surgery but can be addressed with surgery.

\section{Conclusions}

The patient's response to the SF-36 item "Have you felt downhearted and depressed?" accounts for $20 \%$ of the variability in 1-year ODI and EQ-5D scores and can be used by clinicians to help screen for anxiety or depression in patients prior to lumbar fusion surgery. Clinicians may use this information as part of the shared decision-making process or offer psychological support to these patients preoperatively in order to improve treatment outcomes. It is important to recognize that no single data point is likely to optimize patient selection. However, any incremental advantage would be beneficial.

\section{References}

1. Anderson JT, Haas AR, Percy R, Woods ST, Ahn UM, Ahn $\mathrm{NU}$ : Clinical depression is a strong predictor of poor lumbar fusion outcomes among workers' compensation subjects. Spine (Phila Pa 1976) 40:748-756, 2015

2. Asher AL, Speroff T, Dittus RS, Parker SL, Davies JM, Selden N, et al: The National Neurosurgery Quality and Outcomes Database (N2QOD): a collaborative North American outcomes registry to advance value-based spine care. Spine (Phila Pa 1976) 39 (22 Suppl 1):S106-S116, 2014

3. Beck AT, Steer RA, Ball R, Ranieri W: Comparison of Beck Depression Inventories -IA and -II in psychiatric outpatients. J Pers Assess 67:588-597, 1996

4. Berwick DM, Murphy JM, Goldman PA, Ware JE Jr, Barsky AJ, Weinstein MC: Performance of a five-item mental health screening test. Med Care 29:169-176, 1991

5. Brown CW, Orme TJ, Richardson HD: The rate of pseudarthrosis (surgical nonunion) in patients who are smokers and patients who are nonsmokers: a comparison study. Spine (Phila Pa 1976) 11:942-943, 1986

6. Butcher JN, Dahlstrom WG, Graham JR, Tellegen A, Kaemmer B: The Minnesota Multiphasic Personality Inventory-2 (MMPI-2): Manual for Administration and Scoring. Minneapolis: University of Minnesota Press, 1989

7. Bydon M, De la Garza-Ramos R, Abt NB, Gokaslan ZL, Wolinsky JP, Sciubba DM, et al: Impact of smoking on complication and pseudarthrosis rates after single- and 2-level posterolateral fusion of the lumbar spine. Spine (Phila Pa 1976) 39:1765-1770, 2014

8. EuroQol Group: EuroQol-a new facility for the measurement of health-related quality of life. Health Policy 16:199208, 1999

9. Fairbank JC, Couper J, Davies JB, O'Brien JP: The Oswestry low back pain disability questionnaire. Physiotherapy 66:271-273, 1980

10. Fairbank JC, Pynsent PB: The Oswestry Disability Index. Spine (Phila Pa 1976) 25:2940-2952, 2000

11. Glassman SD, Dimar JR III, Burkus K, Hardacker JW, Pryor PW, Boden SD, et al: The efficacy of rhBMP-2 for posterolateral lumbar fusion in smokers. Spine (Phila Pa 1976) 32:1693-1698, 2007

12. Main CJ, Wood PL, Hollis S, Spanswick CC, Waddell G: The Distress and Risk Assessment Method. A simple patient classification to identify distress and evaluate the risk of poor outcome. Spine (Phila Pa 1976) 17:42-52, 1992

13. McCaffery M, Beebe A: Pain: Clinical Manual for Nursing Practice. Baltimore: V.V. Mosby Company, 1993

14. McGirt MJ, Parker SL, Asher AL, Norvell D, Sherry N, Devin CJ: Role of prospective registries in defining the value and effectiveness of spine care. Spine (Phila Pa 1976) 39 (22 Suppl 1):S117-S128, 2014

15. McGirt MJ, Speroff T, Dittus RS, Harrell FE Jr, Asher AL: The National Neurosurgery Quality and Outcomes Database (N2QOD): general overview and pilot-year project description. Neurosurg Focus 34(1):E6, 2013

16. Miller JA, Derakhshan A, Lubelski D, Alvin MD, McGirt MJ, Benzel EC, et al: The impact of preoperative depression on quality of life outcomes after lumbar surgery. Spine J 15:58-64, 2015

17. Parker SL, Godil SS, Zuckerman SL, Mendenhall SK, Devin $\mathrm{CJ}, \mathrm{McGirt}$ MJ: Extent of preoperative depression is associated with return to work after lumbar fusion for spondylolisthesis. World Neurosurg 83:608-613, 2015

18. Rohrer JE: Medical care usage and self-rated mental health. BMC Public Health 4:3, 2004

19. Trief PM, Grant W, Fredrickson B: A prospective study of psychological predictors of lumbar surgery outcome. Spine (Phila Pa 1976) 25:2616-2621, 2000

20. Trief PM, Ploutz-Snyder R, Fredrickson BE: Emotional health predicts pain and function after fusion: a prospective multicenter study. Spine (Phila Pa 1976) 31:823-830, 2006

21. Troidle L, Wuerth D, Finkelstein S, Kliger A, Finkelstein F: The BDI and the SF36: which tool to use to screen for depression? Adv Perit Dial 19:159-162, 2003

22. Wahlman M, Häkkinen A, Dekker J, Marttinen I, Vihtonen $\mathrm{K}$, Neva MH: The prevalence of depressive symptoms before and after surgery and its association with disability in patients undergoing lumbar spinal fusion. Eur Spine J 23:129-134, 2014

23. Ware JE, Snow K, Kosinski M, Gandek B: SF-36 Health Survey: Manual and Interpretations Guide. Boston: The Health Institute, New England Medical Center, 1993

24. Weinstein MC, Berwick DM, Goldman PA, Murphy JM, Barsky AJ: A comparison of three psychiatric screening tests using receiver operating characteristic (ROC) analysis. Med Care 27:593-607, 1989

25. Zigmond AS, Snaith RP: The hospital anxiety and depression scale. Acta Psychiatr Scand 67:361-370, 1983

\section{Disclosures}

Dr. Carreon is an employee of Norton Healthcare, received funding for travel from the Association for Collaborative Spine Research, Center for Spine Surgery and Research at the University of Southern Denmark, and the University of Louisville Institutional Review Board, and has received funds from NuVa- 


\section{Y. Carreon et al.}

sive that were paid directly to a database company. Dr. Crawford is a consultant for Alphatec, Medtronic, Titan, and DePuySynthes. Dr. Djurasovic is an employee of Norton Healthcare and receives consulting fees from Medtronic. Mr. Dimar is an employee of Norton Healthcare, a consultant for Medtronic and DePuy, holds patents with Medtronic, is a board member of the Scoliosis Research Society, is on the editorial boards of JBJS Highlights, Spine, Spine Deformity, JAAOS, and Global Spine, and has received funds from NuVasive that were paid directly to a database company. Dr. Glassman is an employee of Norton Healthcare, receives grant funding from Norton Healthcare and $\mathrm{NuVasive}$ that are directly paid to the database company, holds patents with and receives royalties form Medtronic, and is the past president of the Scoliosis Research Society. Ms. McGraw is an employee of the Norton Leatherman Spine Center. Dr. Owens is an employee of Norton Healthcare and receives consulting fees from Alphatec Spine. Dr. Puno is an employee of Norton Healthcare and holds patents with Medtronic and Alphatec.

\section{Author Contributions}

Conception and design: Carreon. Acquisition of data: all authors. Analysis and interpretation of data: Carreon. Drafting the article: Carreon. Critically revising the article: all authors. Reviewed submitted version of manuscript: all authors. Statistical analysis: Carreon.

\section{Correspondence}

Leah Y. Carreon, Norton Leatherman Spine Center, 210 E. Gray St., Ste.900, Louisville, KY 40202. email: leah.carreon@ nortonhealthcare.org. 